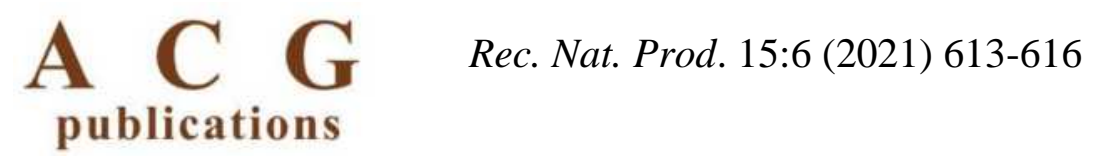

\title{
Eudesmane Sesquiterpenoids from Salvia plebeia
}

\author{
Ying Lu $\oplus^{* 1,2}$ and Yifang Chen $\odot 1$ \\ ${ }^{1}$ Department of Pharmacy, The First People's Hospital of Yuhang District, Hangzhou 311100, China \\ ${ }^{2}$ School of Medicine, Zhejiang University, Hangzhou 310058, China
}

(Received October 22, 2020; Revised November 29, 2020; Accepted December 16, 2020)

\begin{abstract}
A new eudesmane sesquiterpenoid (1), named sapleudesone, together with four known analogs (2-5) were isolated from the aerial parts of Salvia plebeia. The structure of compound $\mathbf{1}$ was established by NMR and HRESIMS data, and the absolute configuration of $\mathbf{1}$ was determined by comparing the experimental ECD spectrum with the calculated ECD spectra. The known compounds were identified to be salplebeone A (2), linderolide I (3), chlorantene D (4), and chlomultin B (5), respectively, by comparing the NMR data and specific rotations with reported data. All five compounds were tested for the inhibitory effects against NO production in LPS-activated RAW 264.7 macrophages. As a result, compound 2 exhibited weak inhibitory effects with an $\mathrm{IC}_{50}$ value of $42.3 \pm$ $1.4 \mu \mathrm{M}$.
\end{abstract}

Keywords: Salvia plebeia; eudesmane sesquiterpene; inhibitory effects; NO production. () 2021 ACG Publications. All rights reserved.

\section{Plant Source}

The aerial parts of Salvia plebeia R. Br. were collected in October 2018 in Jiangsu Province, P. R. China, and were identified by Prof. Jianyong Zhu of Shanghai University of Traditional Chinese Medicine. The voucher specimen (accession number: Sap1201810) was deposited at Zhejiang University (HZU).

\section{Previous Studies}

S. plebeia R. Brown is a biennial herb widely distributed in China, especially in Shaanxi, Jiangsu, Fujian, Guizhou, Hunan, and Guangdong Provinces, it is used for the treatment of bruises, flu, sore throat, pediatric convulsion, and vomiting blood in Traditional Chinese Medicine [1]. Previous chemical investigations of this plant led to the isolation of sesquiterpenoids [2-6], diterpenoids $[7,8]$, and flavonoids [9]. The eudesmane squiterpenoids are major metabolites of this plant, and several cases showed significant anti-inflammatory effects, such as salviplenoid and salviplenoid A $[5,10]$.

\footnotetext{
*Corresponding author: E- Mail: Lu_ying20081030@126.com (Y. Lu).
} 
A new eudesmane sesquiterpenoid

\section{Present Study}

The aerial parts of S. plebeia $(1.0 \mathrm{~kg})$ was extracted with $95 \% \mathrm{EtOH}(4 \times 2 \mathrm{~L})$ at room temperature to give an extract $(98 \mathrm{~g})$. The extract was further suspended in water $(1 \mathrm{~L})$ and extracted with petroleum ether $(4 \times 0.5 \mathrm{~L})$ and EtOAc $(4 \times 0.5 \mathrm{~L})$, respectively. The EtOAc extract $(57 \mathrm{~g})$ was separated on silica gel chromatographic column (CC) gel (petroleum ether/ EtOAc, 10:1 to 1:1) to obtain six fractions (Fra.A- Fra.F). Fra. C was chromatographed over silica gel CC (petroleum ether/acetone, 20:1 to 1:1) to afford three subfractions (Fra.C1-Fra.C3). Fra.C1 was further purified by silica gel CC (petroleum ether/ EtOAc, 10:1 to 5:1) to yield 1. Fra.C2 was purified by silica gel CC (petroleum ether/acetone, 20:1 to 10:1) to give 2, 3, and 5. Fra. C3 was further purified by ODS C18 silica gel CC with $\mathrm{MeOH} / \mathrm{H}_{2} \mathrm{O}$ (60:40 to $90: 10)$ as mobile phase to give 4 .<smiles>CC1=CC(=O)CC2(C)C[C@@H](O)C(C(C)C)CC12</smiles><smiles>CC1=CC(=O)[C@H](O)[C@@]2(C)C=C3OC(=O)C(C)=C3C[C@H]12</smiles><smiles>CC1=C2C[C@H]3[C@@H](C)C(=O)C=C[C@]3(C)C[C@]2(O)OC1=O</smiles><smiles>CC1=C2C(=O)c3c(C)coc3C[C@]2([CH]O)CC1=O</smiles>

4<smiles>CC1=CCC(O)[C@]2(C)Cc3occ(C)c3C(=O)[C@H]12</smiles>

Figure 1. Structures of compounds 1-5

Sapleudesone (1): Colorless oil; $[\alpha]^{25}{ }_{\mathrm{D}}-178(c 0.1, \mathrm{MeOH})$; ECD $\left(c 1.1 \times 10^{-3} \mathrm{M}, \mathrm{MeOH}\right) \lambda_{\max }(\Delta \varepsilon)$ $329(-1.55), 286(-0.81), 241(+11.2) \mathrm{nm}$; HRESIMS $m / z 235.1695[\mathrm{M}+\mathrm{H}]^{+}$(calcd for $\mathrm{C}_{15} \mathrm{H}_{23} \mathrm{O}_{2}$, 235.1698). ${ }^{1} \mathrm{H}$ NMR $\left(400 \mathrm{MHz}, \mathrm{DMSO}-d_{6}\right): \delta_{\mathrm{H}} 5.79(1 \mathrm{H}, \mathrm{s}, \mathrm{H}-3), 4.79(1 \mathrm{H}, \mathrm{s}, \mathrm{H}-12 \mathrm{~b}), 4.78(1 \mathrm{H}, \mathrm{s}, \mathrm{H}-$ 12a), $3.62(1 \mathrm{H}, \mathrm{m}, \mathrm{H}-8), 2.50(1 \mathrm{H}, \mathrm{m}, \mathrm{H}-5), 2.29(1 \mathrm{H}, \mathrm{d}, J=15.0 \mathrm{~Hz}, \mathrm{H}-1 \mathrm{~b}), 2.09(1 \mathrm{H}, \mathrm{d}, J=15.0 \mathrm{~Hz}, \mathrm{H}-$ 1a), $2.03(1 \mathrm{H}, \mathrm{m}, \mathrm{H}-7), 1.87(3 \mathrm{H}, \mathrm{s}, \mathrm{H}-15), 1.81(1 \mathrm{H}, \mathrm{d}, J=13.0,3.4 \mathrm{~Hz}, \mathrm{H}-6 \mathrm{~b}), 1.75(3 \mathrm{H}, \mathrm{s}, \mathrm{H}-13), 1.70$ $(1 \mathrm{H}, \mathrm{dd}, J=12.3,4.6 \mathrm{~Hz}, \mathrm{H}-9 \mathrm{a}), 1.45(1 \mathrm{H}, \mathrm{d}, J=13.0 \mathrm{~Hz}, \mathrm{H}-6 \mathrm{a}), 1.34(1 \mathrm{H}, \mathrm{dd}, J=12.3,11.0 \mathrm{~Hz}, \mathrm{H}-9 \mathrm{~b})$, $0.84(3 \mathrm{H}, \mathrm{s}, \mathrm{H}-14) .{ }^{13} \mathrm{C}$ NMR (100 MHz, DMSO- $\left.d_{6}\right)$ : $\delta_{\mathrm{C}} 197.2$ (C-2), $162.2(\mathrm{C}-4), 146.9(\mathrm{C}-11), 125.3$ (CH-3), $110.9\left(\mathrm{CH}_{2}-12\right), 65.4(\mathrm{CH}-8), 53.5(\mathrm{C}-7), 53.2\left(\mathrm{CH}_{2}-1\right), 47.9\left(\mathrm{CH}_{2}-9\right), 45.8(\mathrm{CH}-5), 37.8(\mathrm{CH}-$ 10), $27.9\left(\mathrm{CH}_{2}-6\right), 21.0\left(\mathrm{CH}_{3}-15\right), 19.3\left(\mathrm{CH}_{3}-13\right), 16.9\left(\mathrm{CH}_{3}-14\right)$.

The molecular formula of compound 1 was established as $\mathrm{C}_{15} \mathrm{H}_{22} \mathrm{O}_{2}$ by HRESIMS data $(\mathrm{m} / \mathrm{z}$ $235.1695[\mathrm{M}+\mathrm{H}]^{+}$, calcd $\left.m / z 235.1698\right)$, suggesting 5 indices of hydrogen deficiency. The ${ }^{1} \mathrm{H}$ NMR spectrum displayed signals for two olefinic methyls $\left(\delta_{\mathrm{H}} 1.87,1.75\right)$, a tertiary methyl $\left(\delta_{\mathrm{H}} 0.84\right)$, three olefinic protons $\left(\delta_{\mathrm{H}} 5.79,4.79,4.78\right)$, an oxygenated proton $\left(\delta_{\mathrm{H}} 3.62\right)$. The ${ }^{13} \mathrm{C}$ NMR spectrum exhibited 15 carbon resonances, including four olefinic carbons for two double bonds $\left(\delta_{\mathrm{C}} 162.2,146.9,125.3\right.$, 110.9), a carbonyl carbon for a ketone $\left(\delta_{C} 197.2\right)$, and an oxygenated methine $\left(\delta_{C} 65.4\right)$. Detailed analyses of the 2D NMR data established an eudesmane sesquiterpene skeleton for compound 1 (Figure 2). Especially, the HMBC correlations from $\mathrm{H}_{3}-15\left(\delta_{\mathrm{H}} 1.87\right)$ to $\mathrm{C}-3\left(\delta_{\mathrm{C}} 125.3\right)$, C-4 $\left(\delta_{\mathrm{C}} 162.2\right)$, and $\mathrm{H}_{2}-$ $1\left(\delta_{\mathrm{H}} 2.29,2.09\right)$ to $\mathrm{C}-2\left(\delta_{\mathrm{C}} 197.2\right)$ assigned an $\alpha, \beta$-unsaturated ketone moiety residing at $\mathrm{C}-2, \mathrm{C}-3$, and C-4. Additional $\mathrm{HMBC}$ correlations from $\mathrm{H}_{3}-13\left(\delta_{\mathrm{H}} 1.75\right)$ and the exomethylene protons $\mathrm{H}_{2}-12\left(\delta_{\mathrm{H}} 4.79\right.$, 4.78) to $\mathrm{C}-7\left(\delta_{\mathrm{C}} 53.5\right)$ and $\mathrm{C}-11\left(\delta_{\mathrm{C}} 146.9\right)$ located an isopropenyl group at $\mathrm{C}-7\left(\delta_{\mathrm{C}} 53.5\right)$. The ${ }^{1} \mathrm{H}-{ }^{1} \mathrm{H}$ COSY correlations from $\mathrm{H}-7\left(\delta_{\mathrm{H}} 2.03\right)$ to $\mathrm{H}_{2}-9\left(\delta_{\mathrm{H}} 1.70,1.34\right)$ via the the oxygenated proton $\mathrm{H}-8$ at $\delta_{\mathrm{H}}$ 3.62 positioned a hydroxyl group at C-8 $\left(\delta_{\mathrm{C}} 65.4\right)$. 


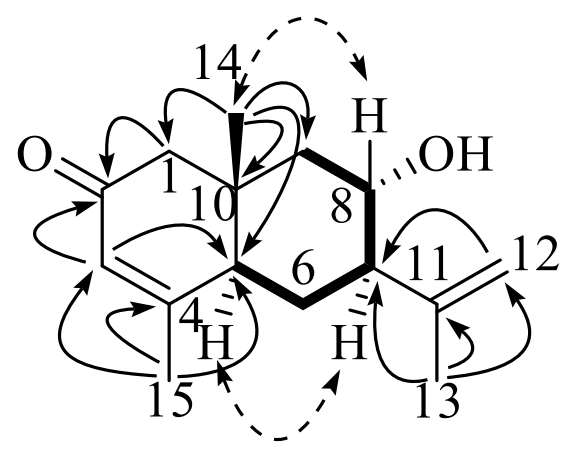

Figure 2. ${ }^{1} \mathrm{H}-{ }^{1} \mathrm{H}$ COSY $(-), \operatorname{HMBC}(\rightarrow)$, and $\operatorname{NOE}(\hookrightarrow)$ correlations of $\mathbf{1}$.

The NOESY correlations of $\mathrm{H}_{3}-14\left(\delta_{\mathrm{H}} 0.84\right)$ with $\mathrm{H}-8\left(\delta_{\mathrm{H}} 3.62\right)$ and between $\mathrm{H}-5\left(\delta_{\mathrm{H}} 2.50\right)$ and $\mathrm{H}-$ $7\left(\delta_{\mathrm{H}} 2.03\right)$ determined the same orientation of $\mathrm{H}_{3}-14$ and $\mathrm{H}-8$, while $\mathrm{H}-5$ and $\mathrm{H}-7$ were in opposite face relative to $\mathrm{H}_{3}-14$ (Figure 2). The absolute configuration of 1 was determined by comparison of its experimental and calculated electronic circular dichroism (ECD) spectra (Figure 3). The experimental ECD spectrum showed positive Cotton effect at $241 \mathrm{~nm}$, which was similar to the Cotton effect of the calculated ECD spectrum of $\mathbf{1 a}(5 R, 7 R, 8 S, 10 S-\mathbf{1})$ at $241 \mathrm{~nm}$, allowing the assignment of the absolute configuration of $\mathbf{1}$ to be $5 R, 7 R, 8 S$, and $10 S$. Compound $\mathbf{1}$ was given the trivial name sapleudesone.

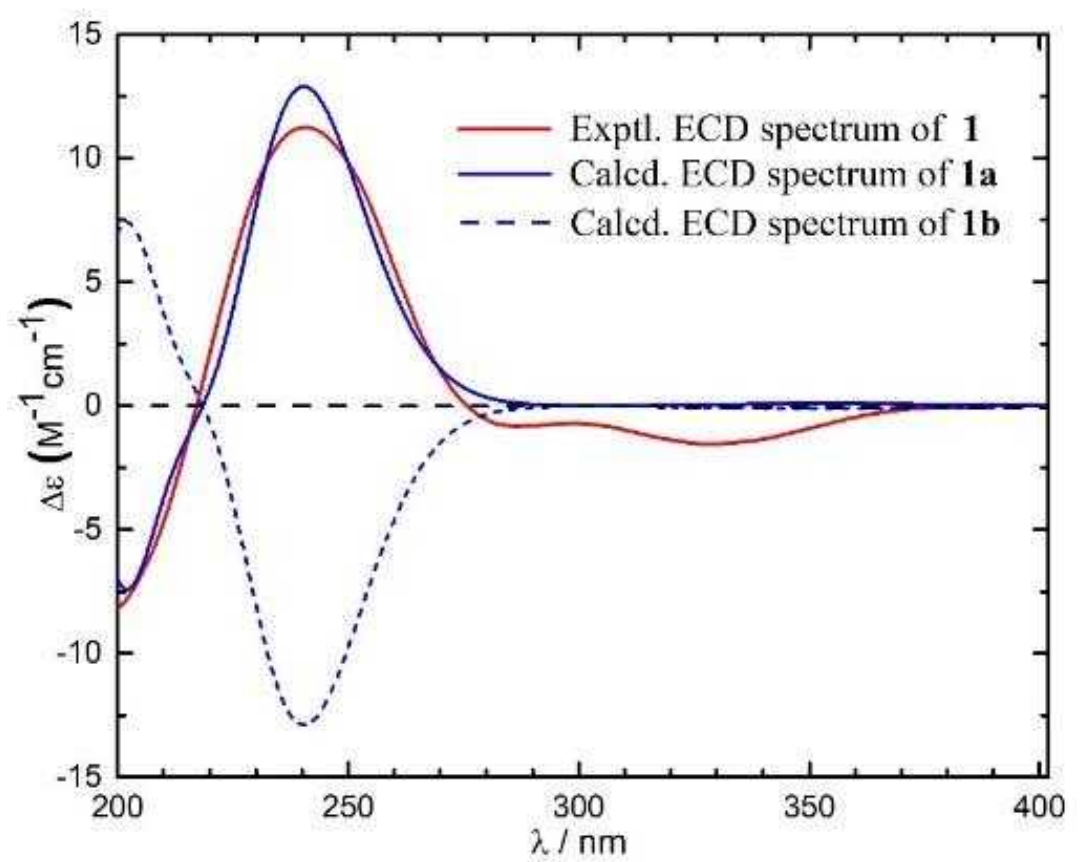

Figure 3. Experimental and calculated ECD spectra $(200-400 \mathrm{~nm})$ of compounds $1,1 a(5 R, 7 R, 8 S$, $10 S)$, and $\mathbf{1 b}(5 S, 7 S, 8 R, 10 R)$.

The known compounds were identified to be salplebeone A (2) [6], linderolide I (3) [11], curcolonol (4) [12], chlomultin B (5) [13], respectively, by comparisons of the NMR data and optical rotations with reported data.

Compounds 1-5 were tested for the inhibitory effects against NO production in LPS-activated RAW 264.7 macrophages following the procedures in the literature [14-16]. As results, only compound 2 exhibited weak inhibition rate of $63.2 \%$ at the initial concentration of $50 \mu \mathrm{M}$ and had an $\mathrm{IC}_{50}$ value of $42.3 \pm 1.4 \mu \mathrm{M}$, other compounds showed inhibition rate less than $30 \%$ at $50 \mu \mathrm{M}$, and the positive control quercetin possessed an $\mathrm{IC}_{50}$ value of $17.5 \pm 1.1 \mu \mathrm{M}$. 
A new eudesmane sesquiterpenoid

\title{
Supporting Information
}

\author{
Supporting Information accompanies this paper on http://www.acgpubs.org/journal/records- \\ of-natural-products \\ ORCID \\ Ying Lu: 0000-0002-4385-0529 \\ Yifang Chen: 0000-0003-3120-7218
}

\section{References}

[1] Y. Q. Chen, D. Z. Cheng, G. F. Wu, P. S. Cheng and P. Z. Zhu (1977). In Chinese Flora (Zhongguo Zhiwu Zhi); Science Press: Beijing, 66, 168-172.

[2] C. G. Zhang, M. R. Jin, G. X. Chou and Q. S. Yang (2017). Plebeins A-F, sesquiterpenoids and diterpenoids from Salvia plebeian, Phytochem. Lett. 19, 254-258.

[3] H. J. Jang, H. M. Oh, J. T. Hwang, M. H. Kim, S. Lee, K. Jung, Y. H. Kim, S. W. Lee and M. C. Rho (2016). Eudesmane-type sesquiterpenoids from Salvia plebeia inhibit IL-6-induced STAT3 activation, Phytochemistry 130, 335-342.

[4] Y. Dai, L. Liu, G. Xie, Y. Chen, X. Qin, Q. Wang, J. Li and M. Qin (2014). Four new eudesmane-type sesquiterpenes from the basal leaves of Salvia plebeia R. Br, Fitoterapia 94, 142-147.

[5] H. J. Jang, S. Lee, S. J. Lee, H. J. Lim, K. Jung, Y. H. Kim, S. W. Lee and M. C. Rho (2017). Antiinflammatory activity of eudesmane-type sesquiterpenoids from Salvia plebeia, J. Nat. Prod. 80, 26662676.

[6] L. F. Ma, P. F. Wang, J. D. Wang, X. M. Tong, W. G. Shan, H. Zhang and Z. J. Zhan (2017). New eudesmane sesquiterpenoids from Salvia plebeia R. Br, Chem. Blodivers. 14, e1700127.

[7] J. Xu, M. Wang, X. Sun, Q. Ren, X. Cao, S. Li, G. Su, M. Tuerhong, D. Lee, Y. Ohizumi, M. Bartlam and Y. Guo (2016). Bioactive terpenoids from Salvia plebeia: Structures, NO Inhibitory activities, and interactions with iNOS, J. Nat. Prod. 79, 2924-2932.

[8] B. B. Zhang, B. Q. He, J. B. Sun, B. Zeng, X.-J. Shi, Y. Zhou, Y. Niu, S. Q. Nie, F. Feng, Y. Liang and F. H. Wu (2015). Diterpenoids from Saliva plebeia R. Br. and their antioxidant and anti-inflammatory activities, Molecules 20, 14879-14888.

[9] Y. Oshima, Y. Kawakami, Y. Kiso, H. Hikino, L. L. Yang and K. Y. Yen (1984). Liver protective drugs. 13. Antihepatotoxic principles of Salvia plebeia herbs, Shoyakugaku Zasshi 38, 201-202.

[10] Y. H. Zou, L. Zhao, Y. K. Xu, J. M. Bao, X. Liu, J. S. Zhang, W. Li, A. Ahmed, S. Yin and G.H. Tang (2018). Anti-inflammatory sesquiterpenoids from the traditional Chinese medicine Salvia plebeia: regulates pro-inflammatory mediators through inhibition of $\mathrm{NF}-\kappa \mathrm{B}$ and Erk1/2 signaling pathways in LPSinduced Raw264.7 cells, J. Ethnopharmacol. 210, 95-106.

[11] Q. Liu, J. H. Ahn, S. B. Kim, C. Lee, B. Y. Hwang and M. K. Lee (2013). Sesquiterpene lactones from the roots of Lindera strychnifolia, Phytochemistry 87, 112-118.

[12] C. Li, D. Zhang and Y. Luo (2005). Studies on the chemical constituents from the roots of Chloranthus henryi, Acta. Pharm. Sin. 40, 525-528.

[13] S. Zhang, Z. S. Su, S. P. Yang and J. M. Yue (2010). Four sesquiterpenoids from Chloranthus multistachys, J. Asian Nat. Prod. 12, 522-528.

[14] Z. Cheng, W. Xu, Y. Wang, S. Bai, L. Liu, Z. Luo, W. Yuan and Q. Li (2019). Two new meroterpenoids and two new monoterpenoids from the deep sea-derived fungus Penicillium sp. YPGA11, Fitoterapia 133, $120-124$.

[15] L. Li, W. Du and W. Wang (2019). Evaluation of the antioxidative and anti-inflammatory effects of the extract of Ribes mandshuricum (Maxim.) Kom. leaves, Rec. Nat. Prod. 13, 141-155.

[16] M. Zhao, G. Chen, T. Lin and Y. Lu (2020). A new labdane diterpene from the aerial parts of Chloranthus serratus, Rec. Nat. Prod. 14, 378-382.

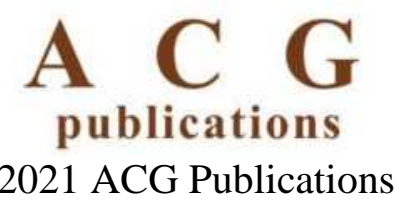

